\title{
Trajectories of Resilience, Resistance, and Distress During Ongoing Terrorism: The Case of Jews and Arabs in Israel
}

\author{
Stevan E. Hobfoll \\ Kent State University \\ Robert J. Johnson \\ University of Miami
}

Brian J. Hall

Kent State University and Rush Medical College

\author{
Patrick A. Palmieri \\ Summa Health System and Kent State University \\ Daphna Canetti-Nisim \\ The MacMillan Center and Yale University
}

\author{
Sandro Galea \\ University of Michigan
}

\begin{abstract}
This is the 1st longitudinal examination of trajectories of resilience and resistance (rather than ill-being) among a national sample under ongoing threat of mass casualty. The authors interviewed a nationally representative sample of Jews and Arabs in Israel $(N=709)$ at 2 times during a period of terrorist and rocket attacks (2004-2005). The resistance trajectory, exhibiting few or no symptoms of traumatic stress and depression at both time points, was substantially less common $(22.1 \%)$ than has previously been documented in studies following single mass casualty events. The resilience trajectory, exhibiting initial symptoms and becoming relatively nonsymptomatic, was evidenced by $13.5 \%$ of interviewees. The chronic distress trajectory was documented among a majority of participants (54.0\%), and a small proportion of persons were initially relatively symptom-free but became distressed (termed delayed distress trajectory; 10.3\%). Less psychosocial resource loss and majority status (Jewish) were the most consistent predictors of resistance and resilience trajectories, followed by greater socioeconomic status, greater support from friends, and less report of posttraumatic growth.
\end{abstract}

Keywords: trauma, terrorism, resilience, PTSD, positive psychology

Supplemental materials: http://dx.doi.org/10.1037/a0014360.supp

Research on terrorism and war and other mass casualty events has overwhelmingly focused on pathological responding, most typically symptoms related to traumatic stress (Bleich, Gelkopf, \& Solomon, 2003; Galea et al., 2002; Hobfoll, Canetti-Nisim, \& Johnson, 2006; Punamäki, Komproe, Qouta, Elmasri, \& de Jong, 2005) and, to a lesser extent, depression (Hobfoll, Tracy, \& Galea, 2006). However, emerging research has suggested that in the aftermath of mass casualty, the majority of persons do not report

Stevan E. Hobfoll, Department of Psychology, Kent State University; Patrick A. Palmieri, Department of Psychiatry, Summa Health System, and Department of Psychology, Kent State University; Robert J. Johnson, Department of Sociology, University of Miami; Daphna Canetti-Nisim, Council on Middle East Studies, The MacMillan Center, and Department of Political Science, Yale University; Brian J. Hall, Department of Psychology, Kent State University, and Department of Behavioral Sciences, Rush Medical College; Sandro Galea, Department of Epidemiology, University of Michigan.

This study was made possible, in part, by grants from the National Institute of Mental Health (R01 MH073687) and the Ohio Board of Regents.

Correspondence concerning this article should be addressed to Stevan E. Hobfoll, who is now at the Department of Behavioral Sciences, Rush Medical College, 1653 West Congress Parkway, Chicago, IL 60612-3244. E-mail: stevan_hobfoll@rush.edu psychological distress and may be termed resistant (Bonanno, Galea, Bucciarelli, \& Vlahov, 2006, 2007). Because we have only begun to study resistance, and in limited contexts, we know little about its prevalence or predictors (Bonanno, 2005; Bonanno, Rennicke, \& Dekel, 2005).

We longitudinally studied symptoms related to traumatic stress and depression among a national sample of Israeli Jews and Arabs during the latter period of the Second Intifada, when there was ongoing terrorism and likelihood of war because mass casualty exposure weighs heavily on such populations (Shalev, Tuval, Frenkiel-Fishman, Hadar, \& Eth, 2006; Somer, Ruvio, Soref, \& Sever, 2005). Our aim was to estimate the prevalence of resistance, resilience, chronic distress, and a failure to remain resistant (i.e., delayed symptom onset) and to predict these outcomes. We believe this is the first longitudinal study of resilience and related trajectories in the face of terrorism and war during a period of ongoing conflict.

Building on the work of Bonanno et al. (2007); Layne, Warren, Shalev, and Watson (2007); and Norris, Stevens, Pfefferbaum, Wyche, and Pfefferbaum (2007), we outline four key symptom trajectories, over time, after traumatic event exposure. In the first trajectory, termed the resistance trajectory (Layne et al., 2007), individuals never develop symptoms of disorder. A second trajectory, termed the resilience trajectory, is characterized by initial 
symptoms followed by recovery. The resilience trajectory is characterized by improvement to levels that indicate absence of psychological symptoms. In using the general term resilience, we center our thinking on work that has defined resilience as the "ability to maintain relatively stable, healthy levels of psychological ... functioning" (Bonanno, 2005, p. 20) in the face of highly disruptive, threatening events. This does not mean that the people are thriving in the face of threat or loss, but that they are retaining relatively good levels of functioning and low levels of symptoms (Antonovsky, 1979). If they are initially affected, they recover these reasonably healthy levels of functioning and low levels of distress in a reasonable amount of time (Antonovsky, 1979; Caplan, 1964; Frankl, 1963; Norris et al., 2007). In the third trajectory, which we term the chronic distress trajectory, individuals who are initially symptomatic remain so over time. The level of symptoms among those showing chronic distress may range from low to high, but all report some ongoing level of distress. The final trajectory, termed the delayed distress trajectory (Bonanno et al., 2007; Layne et al., 2007), is characterized by initial resistance that is lost and gives way to distress. In this discussion, we focus on psychological symptoms of traumatic stress and depressive mood and do not consider other possible ways in which the consequences of traumatic events can manifest, including, for example, migraines, sleep disorder, and general anxiety disorder.

A few recent studies have examined resilience-related processes in the face of terrorism and war. Bonanno et al. (2005) found that high trait self-enhancers, who characteristically use unrealistic, self-serving biases, displayed greater resilience following the September 11 terrorist attacks. Galea et al. (2002), studying Manhattan residents following the September 11 attacks in New York, found that over $40 \%$ did not report any PTSD symptoms. Similarly, Bonanno et al. (2006) found that $65.1 \%$ of the same Manhattan sample reported no or one symptom of PTSD in the 6 months following the World Trade Center attacks. Of those highly exposed in this sample, about one third remained resilient according to these strict criteria. Finally, Fredrickson, Tugade, Waugh, and Larkin (2003) found that many individuals even experience positive emotions in the aftermath of crises and that these limit depression and fuel thriving.

A number of predictors have been associated with resilience or have been called resilience resources, even if they have usually been examined in terms of their association with lack of disorder and not resilience and resistance as we defined them above (Bonanno, 2005). Among demographic variables, having higher education, being male, having higher income, and being a member of a majority ethnic group have been related to more favorable outcomes (Belle, 1990; Bonanno et al., 2007; Norris et al., 2002). It is generally thought that these demographic indicators, in part, reflect having greater access to psychosocial and financial resources (Belle, 1990; Bonanno et al., 2007; Hatch \& Dohrenwend, 2007; Hobfoll, 1989) and that possession of these resources leads to people's greater resilience. The relationship between religious belief and resilience is more mixed (Chen \& Koenig, 2006; Hobfoll, Canetti-Nisim, \& Johnson, 2006; Hobfoll et al., 2008).

Possessing resources and sustaining them (i.e., not losing resources) is also substantively related to trauma resilience (Norris et al., 2002). Bonanno et al. (2007), on the basis of Hobfoll's (1989, 1998) conservation of resources theory, predicted and found that possessing key personal, social, and material resources and not losing such resources following terrorism exposure were major predictors of resilience. Social support, in particular, has often been linked with resilience (Bleich, Gelkopf, Melamed, \& Solomon, 2006; Bonanno et al., 2007; Galea et al., 2002). Resources, however, are not static, and terrorism exposure might reduce resilience to the extent that it resulted in economic and psychosocial resource loss (Bonanno et al., 2007; Norris et al., 2002).

Posttraumatic growth, defined as "positive psychological change experienced as a result of the struggle with highly challenging life circumstances" (Tedeschi \& Calhoun, 2004, p. 1), has been found to be a major personal resource following trauma, especially in health contexts. However, the findings for posttraumatic growth related to terrorism are more mixed (Hobfoll, Canetti-Nisim, \& Johnson, 2006; Hobfoll et al., 2007). There is some support for the finding that sustained posttraumatic growth is required to support resilience processes (Helgeson, Reynolds, \& Tomich, 2006; Tedeschi \& Calhoun, 2004). However, we have found that even sustained attempts to find meaning and draw benefit from terrorism and war are counterproductive for people's well-being (Hobfoll, Canetti-Nisim, \& Johnson, 2006; Hobfoll et al., 2007). We believe that such attempts may falsely raise positive expectations that are never realized when war and terrorism are chronic (Hobfoll et al., 2007; Stasko \& Ickovics, 2007; Zoellner \& Maercker, 2006).

Finally, resistance to distress might decline with increased intensity or continued trauma exposure (Norris et al., 2002). Bleich et al. (2006) found that only $14.4 \%$ of a national Israeli sample was relatively free of symptoms of distress. This might suggest that high levels of resistance are normal only up to a certain point or range of threat or loss. As severe threat continues chronically, those who were originally resistant may become less capable of investing resources in the service of resistance (Hobfoll, 1998; Norris \& Kaniasty, 1996).

Our study examined the prevalence of several theoretically derived symptom trajectories over time in a large sample of Jews and Arabs exposed to ongoing terrorism and war in Israel. We predicted the following:

Hypothesis 1: Persons with more economic and material resources (e.g., those having higher income, higher education, and male gender as well as being members of the majority Jewish group vs. the ethnic minority Arab group) will be more likely to exhibit the resistance and resilience trajectories than the chronic distress trajectory.

Hypothesis 2: Exhibiting the resistance and resilience trajectories (vs. the chronic distress trajectory) will be related to greater social support, lower posttraumatic growth, less terrorism/war exposure, and less resource loss.

Hypothesis 3: Secular individuals will be more likely to exhibit the resilience or resistance trajectory (vs. the chronic distress trajectory) than will the traditionally religious.

Hypothesis 4: Those who initially show resistance but become symptomatic (i.e., exhibiting the delayed distress trajectory) will report fewer resources and more loss than will those who exhibit the resistance trajectory. 
Due to varied prior reports, age and marital status were not included in our predictions; however, we explored these factors as well.

\section{Method}

\section{Data Collection and Sample}

Telephone land lines were randomly selected to obtain a nationally representative sample of Jews and Arabs (18 years of age or older) living in Israel, stratified by region to ensure representation of both Jewish and Arab Israelis. Data were collected between August 17 and September 8, 2004, for the first wave and between July 31 and October 9, 2005, for the second wave. Interviews were conducted in Hebrew, Russian, or Arabic by native-speaking trained interviewers using translated and back-translated questionnaires that were previously validated. The institutional review boards of the authors' universities approved the study, and oral informed consent was obtained from participants.

The response rate among eligible responders was 57\%. This compared favorably with studies in the United States, especially given that the computerized dialing methods in Israel, unlike in the United States, include business phones (approximately 10\%), which are treated as a failed attempt, and that the higher rates in U.S. studies typically do not include unanswered phones (Galea et al., 2002). Studies and reviews suggest that participation rates between $30 \%$ and $70 \%$ are, at most, weakly associated with bias, although bias should always be checked by examining the representativeness of the obtained sample (Galea \& Tracy, 2007).

The sample represented the distribution in the Israeli population on gender, age, place of residence, and voting behavior (Hobfoll, Canetti-Nisim, \& Johnson, 2006). Wave 1 consisted of 1,613 participants. We excluded 897 (55.6\%) cases that dropped out by Time 2 and 7 cases that had insufficient data to determine resistance status at one or both time points. Hence, for the current study we focused on the $709(44.0 \%)$ cases that had valid resistancerelated classifications at Time 1 and Time 2 (1 year later). We used both ordinary least squares and logistic regression to predict dropout. Gender and age were consistently predictive of dropout, and religiousness and ethnicity had borderline effects in some models. However, the significant predictors of dropout (i.e., male gender, younger age, and borderline for Arab ethnicity and traditional religiousness) predicted only about $1 \%$ of the variance for attrition, indicating that attrition bore little relation to the predictors of interest.

\section{Study Instruments}

A structured survey instrument was administered during interviews lasting approximately $30 \mathrm{~min}$. Demographic variables included in the analyses were age in years (18-22, 23-29, 30-39, $40-49,50-59,60+$ ); gender (male, female); income (average, below average, above average); education (high school or less, more than high school); ethnicity (Jew, Arab); religiousness (secular, traditional, religious, very religious/ultra-orthodox); and marital status (single, divorced, separated, widowed, married/ living with partner). All measures have been used in the abovementioned languages in prior work involving several thousand individuals in Israel and have been found to be reliable and valid
(Hobfoll, Canetti-Nisim, \& Johnson, 2006; Hobfoll et al., 2007). Furthermore, all constructs (e.g., terrorism exposure, traumatic stress-related symptoms, depression symptoms) have been applied to Jews and Arabs in Israel and Palestine in prior research and have been found to be reliably and validly applied to these populations (Bleich et al., 2003; de Jong et al., 2001).

Terrorism exposure was assessed by asking participants whether, since the beginning of the Second Intifada, they were in an attack; whether they had a sustained period in which they feared a family member was in an attack; whether a family member or friend was killed; and whether they, a family member, or a close friend were injured in an attack. Responses were recoded into no recent exposure, one type of recent exposure, or two or more types of recent exposure.

We assessed loss of economic and psychosocial resources related to the Second Intifada with a 10-item scale by Norris (2001), recommended by the National Institute of Mental Health for all terrorism-related research following the events of September 11, 2001. The questionnaire (which included items such as "Have you suffered economically as a result of terrorism and war since the Intifada began?" and "There is at least one person whom you know that you like less than you used to because of things that occurred between you since the Intifada began.") was used in previous postterrorism contexts in Israel (Hobfoll, Canetti-Nisim, \& Johnson, 2006). Answers for the items ranged from 0 (not at all) to 3 (to a very great degree). Economic loss was assessed with three items and coded as 0 types of loss or as 1 or more types of loss. Psychosocial resource loss was assessed with seven items whose scores were summed. Such scales are not expected to have internal homogeneity, because one kind of loss does not necessarily mean that another kind occurs, as can be seen with life event scales and terrorism exposure.

Six items were summed to assess posttraumatic growth in a terrorism context (Hobfoll, Canetti-Nisim, \& Johnson, 2006; $\alpha=$ .73 at Time 1 and .77 at Time 2). Participants were asked to indicate "the degree to which you have gained any of the following things in the past three months as a consequence of your experience with recent terrorism and war" on a scale of 0 (not at all) to 3 (extremely). Items included "hope," "sense of confidence," "feeling that my life has purpose," "intimacy with one or more family members," "feeling closer to at least one person," and "intimacy with at least one friend." We also conducted an analog validation study of 245 undergraduate students and found the scale highly correlated $(r=.82)$ with the total score on the Posttraumatic Growth Inventory (Tedeschi \& Calhoun, 2004), a commonly used measure of the posttraumatic growth construct (results available upon request).

Social support was assessed with two single-item categorical indicators addressing satisfaction with perceived social support from family and from friends (Sarason, Sarason, Shearin, \& Pierce, 1987), answered on a 4-point scale ranging from 0 (not at all) to 3 (extremely). The lowest two categories for each item were combined due to infrequent endorsement, yielding trichotomous support indicators.

The 17-item PTSD Symptom Scale (Foa, Riggs, Dancu, \& Rothbaum, 1993) assessed on a 4-point scale ranging from 0 (not at all) to 3 (extremely) the severity of symptoms during the past month related to exposure to a terrorist attack that occurred since the beginning of the Al Aqsa Intifada in September 2000. If more 
than one exposure was noted, respondents related to their exposure in general as is typical for regions that have experienced widespread and multiple exposures (Scholte et al., 2004). Items with responses of 2 (quite a bit) or 3 (extremely) were considered to be clinically significant symptoms $(\alpha=.87$ at Time 1 and .89 at Time 2). As we did not assume diagnostic levels of PTSD, we refer to these as traumatic stress-related symptoms, following Bleich et al. (2006).

A frequently utilized five-item measure of depressive symptoms over the prior 2 weeks, taken from the Patient Health Questionnaire (Spitzer, Kroenke, \& Williams, 1999), was used. Items (e.g., "How often did you feel weariness or lack of energy?" and "How often did you feel, low, depressed or hopeless?") were answered on a 4-point scale ranging from 0 (not at all) to 3 (nearly every day), and alphas were .86 (Time 1) and .82 (Time 2; Tracy, Hobfoll, Canetti-Nisim, $\&$ Galea, 2008). Further, our five-item measure and the original nine-item measure correlated .95 in a second study (Hobfoll et al., 2008).

\section{Analyses}

\section{Classification Confirmation}

Participants were classified into the four trajectories on the basis of their current traumatic stress and depression symptoms. At each time point, respondents were considered resistant if they had no more than one traumatic stress-related symptom and no more than one depression symptom; otherwise, they were considered distressed at those time points. The resistance trajectory was composed of individuals who were resistant (maximum one depression and one traumatic stress-related symptom) at both time points. The resilience trajectory was made up of individuals who were not resistant at Time 1 but who were resistant at Time 2. Respondents who were nonresistant at both time points constituted the chronic distress trajectory group. Finally, those who were resistant at Time 1 but nonresistant at Time 2 made up the delayed distress trajectory group. We conducted 4 (trajectory group) $\times 2$ (time) repeated measures analyses of variance (ANOVAs) on number of traumatic stress symptoms and depression symptoms separately to examine whether the four trajectories reflected their intended differences and not slight inconsequential differences and, in the case of the change groups, whether they represented meaningful changes. Both the means and standard deviations (see Table 1) and ANOVA results clearly indicate that the groups represented the intended trajectories. For traumatic stress symptoms, there was a main effect of group, $F(3,702)=311.62, \eta_{\mathrm{p}}^{2}=.571, p<.001$, a main effect of time, $F(1,702)=8.34, \eta_{\mathrm{p}}^{2}=.012, p<.01$, and a Group $\times$ Time interaction, $F(3,702)=53.34, \eta_{\mathrm{p}}^{2}=.186, p<$ .001 ; for depression symptoms, there was a main effect of group, $F(3,703)=143.57, \eta_{\mathrm{p}}^{2}=.380, p<.001$, a main effect of time, $F(1,703)=8.84, \eta_{\mathrm{p}}^{2}=.012, p<.01$, and a Group $\times$ Time interaction, $F(3,703)=14.58, \eta_{\mathrm{p}}^{2}=.059, p<.001$. Post hoc tests of paired groups indicated that, as expected, the significant interactions were evidenced for the comparisons of the chronic distress group with the resilience group, the chronic distress group with the delayed distress group, the resilience group with the resistance group, the delayed distress group with the resistance group, and the delayed distress group with the resilience group. These were significant at $p<.01$ or greater in each case for both traumatic stress symptoms and depression symptoms. Further, in the two paired groups that were expected to remain unchanged (the chronic distress vs. the resistance group), there was no significant, nor borderline, interaction for either traumatic stress symptoms ( $p=$ $.652)$ or depression symptoms $(p=.346)$.

\section{Analytic Strategy}

Ideally, multinomial logistic regression, which examines all four groups simultaneously, would have been used to examine what predicts exhibiting these trajectories from Time 1 to Time 2; however, in many of the subpopulations in this analysis there was only one observed value for the dependent variable. Thus, we proceeded with parallel bivariate logistic regression analyses in which the resistance and resilience trajectory groups were compared with the chronic distress trajectory group. We also compared the resistance and delayed distress trajectory groups with each other. Bivariate analyses ( $t$ tests for continuous variables and chi-square tests for categorical variables) determined which predictors were associated with the longitudinal resilience trajectories. Significant predictors, at $p<.10$, were included hierarchically in each regression model as appropriate. We implemented an analytic strategy that generally blocked predictors that were similar in nature and timing. Thus, demographic variables that for the most part are fixed (e.g., gender, ethnicity) were entered first. The second block included Time 1 stressor/exposure variables (e.g.,

Table 1

Descriptive Statistics for Mean (SD) PTSD and Depression Symptoms by Trajectory and Time

\begin{tabular}{cccccc}
\hline Symptom and time & Full sample & Chronic distress & Resilience & Resistance & Delayed distress \\
\hline$N$ & $709^{\mathrm{a}}$ & $383^{\mathrm{a}}$ & $96^{\mathrm{a}}$ & 157 & 73 \\
PTSD & & & & & \\
T1 & $4.10(3.81)$ & $6.50(3.41)$ & $3.51(2.02)$ & $0.34(0.47)$ & $0.49(0.50)$ \\
T2 & $3.70(3.94)$ & $6.19(3.70)$ & $0.36(0.48)$ & $0.16(0.37)$ & $2.67(1.84)$ \\
Depression & & & & & \\
T1 & $1.15(1.60)$ & $1.92(1.74)$ & $0.57(1.06)$ & $0.09(0.29)$ & $0.12(0.33)$ \\
T2 & $1.27(1.58)$ & $2.04(1.65)$ & $0.18(0.38)$ & $0.07(0.26)$ & $1.22(1.33)$ \\
\hline
\end{tabular}

Note. $\quad$ PTSD $=$ posttraumatic stress disorder; $\mathrm{T} 1=$ baseline; $\mathrm{T} 2=12$-month follow-up.

${ }^{a}$ Due to missing data, $N$ for the full sample for T1 PTSD, T2 PTSD, and T1 depression was 707, 708, and 707, respectively; $n$ for chronic distress for T1 PTSD, T2 PTSD, and T1 depression was 381, 381, and 382, respectively; and $n$ for resilience for T1 depression was 95 . 
trauma exposure, resource loss) that referred to stressors/exposure occurring in the past. The third block included psychosocial variables assessed currently at Time 1 (e.g., social support). The fourth block included Time 2 recent stressors/exposure, which would have occurred since the Time 1 assessment. The fifth block included current psychosocial variables as assessed at Time 2. Statistical tests within the logistic regressions were evaluated at a .05 alpha level. All analyses were conducted with SPSS 13.0 software.

\section{Results}

Demographic, exposure, and psychosocial descriptive statistics and results of bivariate analyses are presented in Table 2 . At Time $1(n=230 ; 32.4 \%)$ and Time $2(n=253 ; 35.7 \%)$ about one third of the sample qualified as resistant. In terms of trajectories, 157 $(22.1 \%)$ exhibited the resistance trajectory, $96(13.5 \%)$ exhibited the resilience trajectory, $73(10.3 \%)$ exhibited the delayed distress trajectory, and $383(54.0 \%)$ exhibited the chronically distressed trajectory.

\section{Predictors of Resistance}

We first compared those exhibiting the resistance versus the chronic distress trajectory by using hierarchical binomial logistic regression in order to examine the relative contribution of each of the significant bivariate predictors (see Table 2). Odds ratios and associated $95 \%$ confidence intervals for predictors included in each step of the analyses are reported in Table 3. For ease of reference, we always present outcomes vis-à-vis greater inclusion in the more favorable trajectory (e.g., resistance or resilience).

In the first regression step, gender, ethnicity, religiousness, and income were significant demographic predictors of the resistance versus chronic distress trajectory; education level approached significance $(p=.054)$. Being male, Jewish, and secular (rather than traditional religious) were associated with higher likelihood of exhibiting the resistance trajectory. Higher income and higher education were also associated with higher likelihood of exhibiting the resistance trajectory. Less psychosocial resource loss and less economic loss at Time 1, controlling for demographics, were associated with higher likelihood of exhibiting the resistance trajectory. Controlling for demographics, less psychosocial resource loss, and less economic loss at Time 1, (a) high (vs. low) support from friends at Time 1 was associated with higher likelihood of the resistance trajectory and (b) lower level of traumatic growth was associated with higher likelihood of the resistance trajectory. Controlling for all Time 1 predictors, less psychosocial resource loss at Time 2 was associated with higher likelihood of the resistance trajectory. Finally, controlling for all preceding variables, the fifth block revealed that Time 2 high (vs. low) social support from friends was associated with a higher likelihood of the resistance trajectory. Gender, ethnicity, religiousness, income, education, and psychosocial resource loss at both time points, initially entered in previous steps, also were significant in this full model.

\section{Predictors of Resilience}

We next compared the resilience trajectory group with the chronic distress trajectory group. We included those variables that were significant at the bivariate level (see Table 2) as we con- ducted the hierarchical binomial logistic regression that is reported in Table 4. Significant Block 1 demographic predictors of the resilience versus chronic distress trajectory were ethnicity and income, such that being Jewish and having a higher income were related to greater likelihood of the resilience trajectory. In the next step, Time 1 lower psychosocial resource loss was associated with a higher likelihood of exhibiting the resilience trajectory. Subsequent steps indicated that less psychosocial resource loss assessed at Time 2 and less traumatic growth assessed at Time 2 were associated with higher likelihood of exhibiting the resilience trajectory. There also was a trend ( $p=.064$ ) for high (vs. low) Time 2 social support from friends to be associated with a higher likelihood of the resilience trajectory. Ethnicity, income, and Time 2 (but not Time 1) psychosocial resource loss, initially entered in previous steps, also were significant in this full model.

\section{Predictors of the Delayed Distress Trajectory Compared With the Resistance Trajectory}

We also thought it instructive to compare predictors of the delayed distress trajectory with predictors of the resistance trajectory, because those individuals in the delayed distress trajectory were resistant at one time point but then became symptomatic. Significant bivariate predictors were ethnicity, $\chi^{2}(230)=9.71$, $p<.01$; income, $\chi^{2}(206)=10.52, p<.01$; education, $\chi^{2}(229)=$ 17.47, $p<.001$; religiousness, $\chi^{2}(228)=9.05, p<.05$; Time 2 support from friends, $\chi^{2}(223)=6.02, p<.05$; Time 2 resource loss, $t(228)=4.84, p<.001$, and Time 2 posttraumatic growth, $t(228)=2.43, p<.05$. These predictors were placed in a hierarchical binomial logistic regression, reported in Table 5. Significant demographic predictors in Block 1 were education and religiousness, with having higher education and being secular (vs. traditionally religious) being associated with exhibiting the resistance trajectory. There also were trends for ethnicity $(p=.071)$ and income ( $p=.077)$, with Jews and those with higher income more likely to exhibit the resistance trajectory. In the next step, controlling for all demographic predictors, more psychosocial resource loss reported at Time 2 was associated with a lower likelihood of exhibiting the resistance trajectory. Neither social support nor traumatic growth reported at Time 2 were significant predictors. In the full model, education and Time 2 psychosocial resource loss remained significant, while ethnicity $(p=.056)$ and being secular ( $p=.075)$ versus traditionally religious approached significance.

\section{Supplementary Analyses of Posttraumatic Growth}

It has been suggested by some that posttraumatic growth would have positive impact when it is sustained over a period of time (Tedeschi \& Calhoun, 2004), so we examined this possibility post hoc so as to not inadvertently disguise a beneficial effect for posttraumatic growth. Thus, we repeated our regression analyses after replacing any bivariately significant Time 1 and Time 2 posttraumatic growth indicators with a bivariately significant dichotomous posttraumatic growth indicator (added in the last step) that reflected whether or not there was high sustained growth (i.e., upper tercile at Time 1 and Time 2). The results of these regression analyses were consistent with those from the main analyses (see online supplemental materials link at the beginning of the article). 
Table 2

The Chronic Distress Trajectory vs. the Resilience and Resistance Trajectories: Sample Characteristics and Bivariate Associations Between Study Variables and Trajectories

\begin{tabular}{|c|c|c|c|c|c|c|}
\hline \multirow[b]{2}{*}{ Variable } & \multirow{2}{*}{$\begin{array}{l}\text { Full sample } \\
n(\%)\end{array}$} & \multirow{2}{*}{$\begin{array}{c}\text { Chronic distress } \\
n(\%)\end{array}$} & \multicolumn{2}{|c|}{ Resilience } & \multicolumn{2}{|c|}{ Resistance } \\
\hline & & & $n(\%)$ & $\chi^{2}$ & $n(\%)$ & $\chi^{2}$ \\
\hline$N$ & 709 & 383 & 96 & & 157 & \\
\hline \multicolumn{7}{|c|}{ Categorical variables } \\
\hline Gender & & & & 0.03 & & $11.83^{* * *}$ \\
\hline Male & $316(44.6)$ & $155(40.0)$ & $38(39.6)$ & & $89(56.7)$ & \\
\hline Female & $393(55.4)$ & $228(60.0)$ & $58(60.4)$ & & $68(43.3)$ & \\
\hline Ethnicity & & & & $26.29^{* * * *}$ & & $66.52^{* * *}$ \\
\hline Arab & $143(20.2)$ & $129(34.0)$ & $7(7.3)$ & & $1(0.6)$ & \\
\hline Jewish & $566(79.8)$ & $254(66.0)$ & $89(92.7)$ & & $156(99.4)$ & \\
\hline Income & & & & $28.33^{* * * *}$ & & $60.38^{* * * *}$ \\
\hline Average or below & $435(65.2)$ & $287(78.0)$ & $46(50.0)$ & & $59(42.0)$ & \\
\hline Above average & $232(34.8)$ & $82(22.0)$ & $46(50.0)$ & & $82(58.0)$ & \\
\hline Education & & & & $5.72^{*}$ & & $21.02^{* * * *}$ \\
\hline High school or less & $274(38.9)$ & $170(44.7)$ & $30(31.3)$ & & $37(23.6)$ & \\
\hline More than high school & $431(61.1)$ & $210(55.3)$ & $66(68.8)$ & & $120(76.4)$ & \\
\hline Family status & & & & 0.11 & & 0.02 \\
\hline Single $^{\mathrm{a}}$ & $220(31.0)$ & $117(30.5)$ & $31(32.3)$ & & 47 (29.9) & \\
\hline Married $^{\mathrm{b}}$ & $489(69.0)$ & $266(69.5)$ & $65(67.7)$ & & $110(70.1)$ & \\
\hline Religiousness & & & & $17.76^{* * *}$ & & $49.29^{* * * *}$ \\
\hline Secular & $426(60.4)$ & $186(48.8)$ & $68(70.8)$ & & $125(80.1)$ & \\
\hline Traditional & $178(25.2)$ & $132(34.6)$ & $17(17.7)$ & & $13(8.3)$ & \\
\hline Religious & $76(10.8)$ & $50(13.1)$ & $6(6.3)$ & & $13(8.3)$ & \\
\hline Very religious & $25(3.5)$ & $13(3.4)$ & $5(5.2)$ & & $5(3.2)$ & \\
\hline Age in years & & & & 5.43 & & 6.74 \\
\hline $18-22$ & $69(9.7)$ & $42(11.0)$ & $11(11.5)$ & & $8(5.1)$ & \\
\hline $23-29$ & $88(12.4)$ & $49(12.8)$ & $8(8.3)$ & & $22(14.1)$ & \\
\hline $30-39$ & $149(21.0)$ & $81(21.1)$ & $20(20.8)$ & & $36(23.1)$ & \\
\hline $40-49$ & $126(17.8)$ & $67(17.5)$ & $24(25.0)$ & & $27(17.3)$ & \\
\hline $50-59$ & $150(21.2)$ & $69(18.0)$ & $20(20.8)$ & & 37 (23.7) & \\
\hline $60+$ & $126(17.8)$ & 75 (13.9) & $13(13.5)$ & & $26(16.7)$ & \\
\hline Economic loss & & & & 1.11 & & $14.34^{* * * *}$ \\
\hline No & $552(77.9)$ & $279(72.8)$ & $75(78.1)$ & & $138(87.9)$ & \\
\hline 1 or more & $157(22.1)$ & $104(27.2)$ & $21(21.9)$ & & $19(12.1)$ & \\
\hline $\mathrm{T} 1$ recent exposure & & & & 0.03 & & 0.92 \\
\hline No & $270(43.6)$ & $150(44.2)$ & $38(43.2)$ & & $53(40.8)$ & \\
\hline 1 & $153(24.7)$ & $87(25.7)$ & $23(26.1)$ & & $32(24.6)$ & \\
\hline 2 or more & $196(31.7)$ & $102(30.1)$ & $27(30.7)$ & & $45(34.6)$ & \\
\hline $\mathrm{T} 2$ recent exposure & & & & 0.22 & & 0.65 \\
\hline No & $657(92.7)$ & $354(92.4)$ & $86(92.7)$ & & $147(93.6)$ & \\
\hline 1 & $19(2.7)$ & $11(2.9)$ & $2(2.1)$ & & $5(3.2)$ & \\
\hline 2 or more & $33(4.7)$ & $18(4.7)$ & $5(5.2)$ & & $5(3.2)$ & \\
\hline T1 support from family & & & & 4.49 & & $10.25^{\text {** }}$ \\
\hline Not at all/a little bit & $41(5.9)$ & $31(8.2)$ & $3(3.2)$ & & $4(2.6)$ & \\
\hline Quite a bit & $125(17.9)$ & $70(18.6)$ & $24(25.5)$ & & $19(12.2)$ & \\
\hline To a very great degree & $532(76.2)$ & $275(73.1)$ & $67(71.3)$ & & $133(85.3)$ & \\
\hline $\mathrm{T} 2$ support from family & & & & 3.02 & & $8.75^{*}$ \\
\hline Not at all/a little bit & $52(7.4)$ & $36(9.6)$ & $4(4.2)$ & & $7(4.5)$ & \\
\hline Quite a bit & $148(21.2)$ & $86(22.9)$ & $25(26.0)$ & & $24(15.5)$ & \\
\hline To a very great degree & $499(71.4)$ & $254(67.6)$ & $67(69.8)$ & & $124(80.0)$ & \\
\hline $\mathrm{T} 1$ support from friends & & & & 3.33 & & $27.60^{* * * *}$ \\
\hline Not at all/a little bit & $73(10.4)$ & $53(14.1)$ & $7(7.3)$ & & $6(3.8)$ & \\
\hline Quite a bit & $183(26.1)$ & $113(30.0)$ & $29(30.2)$ & & $26(16.7)$ & \\
\hline To a very great degree & $445(63.5)$ & $211(56.0)$ & $60(62.5)$ & & $124(79.5)$ & \\
\hline $\mathrm{T} 2$ support from friends & & & & $9.25^{* *}$ & & $36.47^{\text {**** }}$ \\
\hline Not at all/a little bit & $81(11.8)$ & $67(18.1)$ & $6(6.3)$ & & $4(2.6)$ & \\
\hline Quite a bit & $218(31.6)$ & $126(34.0)$ & $31(32.6)$ & & $36(23.4)$ & \\
\hline To a very great degree & $390(56.6)$ & $178(48.0)$ & $58(61.1)$ & & $114(74.0)$ & \\
\hline
\end{tabular}


Table 2 (continued)

\begin{tabular}{|c|c|c|c|c|c|c|}
\hline \multirow[b]{2}{*}{ Variable } & \multirow{2}{*}{$\begin{array}{l}\text { Full sample } \\
M(S D)\end{array}$} & \multirow{2}{*}{$\begin{array}{c}\text { Chronic distress } \\
M(S D)\end{array}$} & \multicolumn{2}{|c|}{ Resilience } & \multicolumn{2}{|c|}{ Resistance } \\
\hline & & & $M(S D)$ & $t(d f)$ & $M(S D)$ & $t(d f)$ \\
\hline \multicolumn{7}{|c|}{ Continuous variables } \\
\hline $\mathrm{T} 1$ loss of resources & $8.49(4.93)$ & $10.47(4.66)$ & $7.81(4.46)$ & $5.03(477)^{* * * *}$ & $5.36(3.79)$ & $12.16(538)^{\text {**** }}$ \\
\hline T1 PTG & $5.25(4.68)$ & $6.37(4.66)$ & $5.57(4.85)$ & $1.50(477)$ & $3.12(3.85)$ & $7.73(538)^{* * * *}$ \\
\hline $\mathrm{T} 2$ loss of resources & $6.96(5.06)$ & $9.10(4.93)$ & $4.88(3.83)$ & $7.83(476)^{* * *}$ & $3.44(3.35)$ & $13.20(537)^{* * *}$ \\
\hline T2 PTG & $4.47(4.63)$ & $6.17(5.01)$ & $2.27(2.51)$ & $7.37(477)^{* * * *}$ & $2.22(3.18)$ & $9.13(538)^{* * * *}$ \\
\hline
\end{tabular}

Note. Numbers within categories may not add up to total for some variables due to missing data. Significant statistical test results indicate which variables are bivariately associated with dichotomous trajectory variables (resistance vs. chronic distress; resilience vs. chronic distress). T1 = baseline; $\mathrm{T} 2=$ 12-month follow-up; PTG = posttraumatic growth.

${ }^{a}$ Single/divorced/separated/widowed. ${ }^{\mathrm{b}}$ Married/living with partner.

${ }^{*} p<.05$. $^{* * *} p<.01$. $^{* * * *} p<.001$.

\section{Discussion}

A sizable minority of individuals in this study displayed a resistant trajectory $(22.1 \%)$, having no more than one symptom of depression and no more than one traumatic stress-related symptom at either time point. A small group (13.5\%) of individuals showed a resilience trajectory in that they were not initially resistant but became relatively free of symptoms over time. The most common trajectory was that of chronic distress (54.0\%), and an additional small group of individuals displayed a delayed distress trajectory such that they were initially resistant but became symptomatic over time (10.3\%). In comparison, Bleich et al. (2006) found that $14.4 \%$ of an Israeli sample were resistant, as defined by an absence of symptoms assessed at one time point, and Bonanno et al. (2006) found that resistance of Manhattan residents following the World Trade Center attacks, defined by an absence of symptoms assessed at one time point, was not less than 50\% for most groups and never fell below one third for even the most exposed groups.

Demographic predictors that distinguished the resistance trajectory from the chronic distress trajectory included being male, having higher income, being secular (vs. being traditionally religious), having higher education, and being a member of the majority Jewish ethnic group. As predicted, experiencing less psychosocial resource loss at either time point predicted the resistance trajectory, and perceiving high levels of support (from friends as assessed at Time 2) also was related to exhibiting a resistance pattern. Demographic predictors of the resilience trajectory included having higher income and being Jewish. Lower Time 2 psychosocial resource loss and lower Time 2 traumatic growth also predicted the resilience trajectory, and there was marginal support for high social support from friends at Time 2 predicting this resilience pattern. Although the findings for these two trajectories are not entirely consistent, it appears that the process of resource loss, in particular, undermines sustaining resistance and recovering resiliency and that possessing greater resources-as indicated by having majority status, higher income, and greater social support from friends-also contributes to resistance and resilience trajectories (Hobfoll, 1989, 2002).

Those who displayed the delayed distress trajectory were also compared with those exhibiting the resistance trajectory. Those with lower education and more psychosocial resource loss were more likely to be in the delayed distress group, again indicating the key role of having and sustaining greater resources.
Arabs' lower resilience and resistance mirrors prior findings of the greater vulnerability of ethnic minority individuals when facing trauma and mass casualty (Galea et al., 2002; Norris et al., 2002). Arabs in Israel are exposed to historic discrimination and fewer resources than are Jews and are not well assimilated into Israeli society (Smooha, 2004). Thus, the lower resistance and resilience trajectories of Israeli Arabs may reflect their exposure to other kinds of stressors that we did not evaluate, as they are also exposed to greater security checks, suspiciousness when among the Jewish population, and a sense of loss over what occurs to Palestinians in the Occupied Territories.

Our study and Bleich et al.'s (2006) suggest that the appreciably higher prevalence of resilience and resistance found in New York after the attack on the World Trade Center was, in part, due to the lower levels of and less chronic exposure to terrorism and, hence, less sustained resource loss brought about by the devastating but one-time attack (Bonanno et al., 2006). Although the destruction of the World Trade Center was followed by a series of threatening anthrax attacks, some emanating from the New York metropolitan area, this did not seem to be as depleting of resistance and resilience as are chronic states of conflict.

Contrary to our prediction, terrorism exposure was not related to resilience or resistance. This may be due to such a large percentage of Israeli Jews and Arabs who were exposed to war and terrorismrelated trauma. Some of this trauma is indirect; but, for instance, fear of one's children being killed while on a school bus or at a pizza parlor are significant exposure variables and are, in some ways, more severe than are direct exposure indicators (Galea et al., 2002). Some studies have also found a lack of relationship between exposure and psychological distress (Bleich et al., 2003), whereas others have found a marked association (Galea et al., 2002). Because future threat is by definition ambiguous, this may be a major factor affecting individual differences solely on the basis of past exposure.

Our findings provide some further indication that posttraumatic growth was related to the lower likelihood of resilience and the higher likelihood of chronic distress. During ongoing political conflicts, the lack of expectations for positive change may undermine posttraumatic growth's beneficial impact on symptoms. In such circumstances, posttraumatic growth may be a form of emotion-focused coping that leads to a false sense of positive expectations. Alternatively, posttraumatic growth may reflect an attempt to claim a kind of resilience (i.e., the feeling that one has 
Table 3

Multivariate Associations Comparing the Resistance Trajectory With the Chronic Distress Trajectory by Means of Odds Ratios (95\% Confidence Intervals)

\begin{tabular}{|c|c|c|c|c|c|}
\hline Variable & Step 1 & Step 2 & Step 3 & Step 4 & Step 5 \\
\hline \multicolumn{6}{|l|}{ Gender } \\
\hline Male & 1.00 & 1.00 & 1.00 & 1.00 & 1.00 \\
\hline Female & $0.50(0.31-0.82)^{* *}$ & $0.45(0.26-0.78)^{* *}$ & $0.44(0.24-0.80)^{* * *}$ & $0.46(0.24-0.87)^{*}$ & $0.40(0.21-0.78)^{* * *}$ \\
\hline \multicolumn{6}{|l|}{ Ethnicity } \\
\hline Jewish & 1.00 & 1.00 & 1.00 & 1.00 & 1.00 \\
\hline Arab & $0.02(0.00-0.14)^{* * * *}$ & $0.03(0.00-0.20)^{* * * * *}$ & $0.03(0.00-0.20)^{\text {******* }}$ & $0.02(0.00-0.18)^{* * * *}$ & $0.02(0.00-0.20)^{* * *}$ \\
\hline \multicolumn{6}{|l|}{ Income } \\
\hline Average or below & 1.00 & 1.00 & 1.00 & 1.00 & 1.00 \\
\hline Above average & $3.15(1.94-5.12)^{* * * *}$ & $2.67(1.54-4.63)^{* * * *}$ & $2.56(1.42-4.59)^{* * *}$ & $2.17(1.16-4.06)^{*}$ & $2.23(1.17-4.22)^{*}$ \\
\hline \multicolumn{6}{|l|}{ Education } \\
\hline High school or less & 1.00 & 1.00 & 1.00 & 1.00 & 1.00 \\
\hline More than high school & $1.72(0.99-2.97)^{\dagger}$ & $2.11(1.14-3.90)^{*}$ & $2.08(1.10-3.95)^{*}$ & $2.34(1.19-4.61)^{*}$ & $2.29(1.15-4.56)^{*}$ \\
\hline \multicolumn{6}{|l|}{ Religiousness } \\
\hline Secular & 1.00 & 1.00 & 1.00 & 1.00 & 1.00 \\
\hline Traditional & $0.29(0.14-0.60)^{* * *}$ & $0.34(0.15-0.78)^{*}$ & $0.31(0.13-0.74)^{* * *}$ & $0.31(0.13-0.75)^{* * *}$ & $0.30(0.12-0.74)^{\text {*** }}$ \\
\hline Religious & $0.84(0.36-1.96)$ & $0.67(0.27-1.68)$ & $0.67(0.25-1.82)$ & $0.77(0.26-2.29)$ & $0.82(0.27-2.50)$ \\
\hline Very religious & $0.75(0.22-2.56)$ & $0.80(0.21-3.12)$ & $0.64(0.16-2.51)$ & $0.89(0.21-3.80)$ & $0.88(0.21-3.63)$ \\
\hline \multicolumn{6}{|l|}{ Economic loss } \\
\hline No & & 1.00 & 1.00 & 1.00 & 1.00 \\
\hline 1 or more & & $0.46(0.22-0.93)^{*}$ & $0.52(0.25-1.07)^{\dagger}$ & $0.56(0.26-1.22)$ & $0.63(0.28-1.39)$ \\
\hline $\mathrm{T} 1$ loss of resources & & $0.79(0.74-0.85)^{* * * *}$ & $0.81(0.75-0.87)^{\text {***** }}$ & $0.89(0.82-0.96)^{* *}$ & $0.87(0.80-0.95)^{* *}$ \\
\hline \multicolumn{6}{|l|}{ T1 social support-family } \\
\hline Not at all & & & 1.00 & 1.00 & 1.00 \\
\hline Some & & & $0.56(0.11-2.72)$ & $0.38(0.07-1.97)$ & $0.37(0.06-2.29)$ \\
\hline To a very great degree & & & $1.02(0.23-4.48)$ & $0.67(0.15-3.07)$ & $0.98(0.16-5.82)$ \\
\hline \multicolumn{6}{|l|}{ T1 social support-friend } \\
\hline Not at all & & & 1.00 & 1.00 & 1.00 \\
\hline Some & & & $2.16(0.47-9.88)$ & $2.61(0.51-13.32)$ & $1.24(0.22-6.95)$ \\
\hline To a very great degree & & & $5.94(1.35-26.11)^{*}$ & $5.75(1.18-28.08)^{*}$ & $2.18(0.39-12.31)$ \\
\hline T1 PTG & & & $0.93(0.86-1.00)^{*}$ & $0.95(0.88-1.02)$ & $0.98(0.90-1.07)$ \\
\hline $\mathrm{T} 2$ loss of resources & & & & $0.80(0.73-0.87)^{* * * * *}$ & $0.81(0.74-0.89)^{\text {**** }}$ \\
\hline \multicolumn{6}{|l|}{$\mathrm{T} 2$ social support-family } \\
\hline Not at all & & & & & 1.00 \\
\hline Some & & & & & $0.97(0.23-4.00)$ \\
\hline To a very great degree & & & & & $0.56(0.14-2.72)$ \\
\hline \multicolumn{6}{|l|}{$\mathrm{T} 2$ social support-friends } \\
\hline Not at all & & & & & 1.00 \\
\hline Some & & & & & $4.84(0.92-25.50)^{\dagger}$ \\
\hline To a very great degree & & & & & $8.03(1.42-45.40)^{*}$ \\
\hline T2 PTG & & & & & $0.93(0.85-1.02)$ \\
\hline
\end{tabular}

Note. Significant odds ratios greater (less) than 1.00 are associated with a higher (lower) likelihood of resistance. T1 = baseline; T2 $=12$-month follow-up; PTG $=$ posttraumatic growth.

${ }^{\dagger} p<.10 .{ }^{*} p<.05 .{ }^{* * *} p<.01 .{ }^{* * * *} p<.001$.

grown from the experience when, in fact, the opposite is being felt), in an ineffective attempt to have something good emerge from tragedy.

This study had several limitations. Although our follow-up rates are typical of such studies (Galea \& Tracy 2007), it is possible that the persons who were lost to follow-up are systematically different from those who were followed up. However, loss to follow-up was nondifferential on the key dependent variables of interest and determined by only two independent variables, both of which were accounted for in the final models. Although this does not definitively rule out bias, it provides reassurance that the observations documented here are nonspurious. Further, our findings do not reflect in-depth clinical judgment, and we cannot rule out other disorders. Similarly, there are other predictors of trauma-related distress and depression that may be important (Ehring, Ehlers, \& Glucksman, 2008). Cross-cultural com- parability is also a concern, as such ongoing conflicts may cue other important adaptive systems concerning safety, attachment, justice, and existential meaning (Silove, 1999) that we did not assess but that may relate to trauma among those responding in such circumstances. Nevertheless, according to Bass, Bolton, and Murray's (2007) criteria that measures should be valid in the target culture, traumatic stress symptoms and depression have been shown to apply well to both Jews and Arabs in this specific region (Bleich et al., 2003; de Jong et al., 2001; Hobfoll, Canetti-Nisim, \& Johnson, 2006; Hobfoll et al., 2007 Punamäki et al., 2005).

Some have cautioned about the overuse of the PTSD concept when individuals were not clearly exposed to trauma (Galea \& Resnick, 2005). We did not address diagnosis, but clearly those sampled often have symptoms of distress related to their exposure to war and terrorism. Further, such symptoms are the ones 
Table 4

Multivariate Associations Comparing the Resilience Trajectory With the Chronic Distress

Trajectory by Means of Odds Ratios (95\% Confidence Intervals)

\begin{tabular}{|c|c|c|c|c|}
\hline Variable & Step 1 & Step 2 & Step 3 & Step 4 \\
\hline \multicolumn{5}{|l|}{ Ethnicity } \\
\hline Jewish & 1.00 & 1.00 & 1.00 & 1.00 \\
\hline Arab & $0.20(0.09-0.46)^{* * * *}$ & $0.21(0.09-0.49)^{* * * *}$ & $0.17(0.07-0.42)^{* * *}$ & $0.25(0.10-0.61)^{* * *}$ \\
\hline \multicolumn{5}{|c|}{ 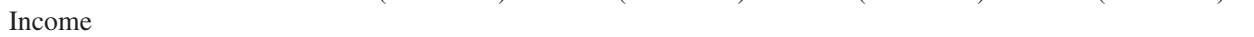 } \\
\hline Average or below & 1.00 & 1.00 & 1.00 & 1.00 \\
\hline Above average & $2.92(1.74-4.88)^{* * * *}$ & $2.92(1.71-4.97)^{* * * * *}$ & $2.56(1.45-4.50)^{* * *}$ & $2.59(1.44-4.64)^{* * *}$ \\
\hline \multicolumn{5}{|c|}{ 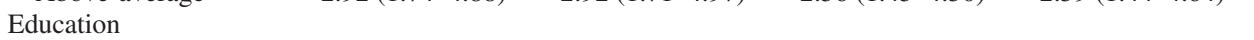 } \\
\hline High school or less & 1.00 & 1.00 & 1.00 & 1.00 \\
\hline More than high school & $1.15(0.67-1.96)$ & $1.30(0.75-2.25)$ & $1.60(0.89-2.90)$ & $1.42(0.77-2.61)$ \\
\hline \multicolumn{5}{|c|}{ Religiousness } \\
\hline Secular & 1.00 & 1.00 & 1.00 & 1.00 \\
\hline Traditional & $0.59(0.32-1.11)$ & $0.62(0.33-1.19)$ & $0.56(0.28-1.10)^{\dagger}$ & $0.63(0.31-1.28)$ \\
\hline Religious & $0.53(0.19-1.47)$ & $0.43(0.15-1.25)$ & $0.50(0.16-1.52)$ & $0.58(0.19-1.84)$ \\
\hline Very religious & $1.39(0.45-4.25)$ & $1.24(0.39-3.97)$ & $1.37(0.39-4.79)$ & $1.49(0.40-5.54)$ \\
\hline $\mathrm{T} 1$ loss of resources & & $0.87(0.82-0.92)^{* * * * * *}$ & $0.95(0.88-1.02)$ & $0.96(0.89-1.03)$ \\
\hline $\mathrm{T} 2$ loss of resources & & & $0.80(0.74-0.87)^{* * * *}$ & $0.83(0.76-0.90)^{\text {******* }}$ \\
\hline \multicolumn{5}{|l|}{ T2 social support-friends } \\
\hline Not at all & & & & 1.00 \\
\hline Some & & & & $2.56(0.89-7.35)^{\dagger}$ \\
\hline To a very great degree & & & & $2.59(0.95-7.09)^{\dagger}$ \\
\hline T2 PTG & & & & $0.87(0.80-0.95)^{* * *}$ \\
\hline
\end{tabular}

Note. Significant odds ratios greater (less) than 1.00 are associated with a higher (lower) likelihood of resilience. $\mathrm{T} 1=$ baseline; $\mathrm{T} 2=12$-month follow-up; PTG $=$ posttraumatic growth.

${ }^{\dagger} p<.10 .{ }^{* * *} p<.01 .{ }^{* * * *} p<.001$.

being cited internationally when examining symptomatic reaction to terrorism and war (Bleich et al., 2006, 2003; Galea et al., 2002; Punamäki et al., 2005).
The study also had important strengths. We believe it is the first longitudinal study of resilience and resistance in the face of ongoing threat from terrorism and war. Second, the large sample size

Table 5

Multivariate Associations Comparing the Delayed Distress Trajectory With the Resistance Trajectory by Means of Odds Ratios (95\% Confidence Intervals)

\begin{tabular}{lccc}
\hline \multicolumn{1}{c}{ Variable } & Step 1 & Step 2 & Step 3 \\
\hline $\begin{array}{l}\text { Ethnicity } \\
\text { Jewish }\end{array}$ & 1.00 & & \\
$\quad$ Arab & $0.13(0.01-1.20)^{\dagger}$ & $0.11(0.01-1.10)^{\dagger}$ & $0.11(0.01-1.06)^{\dagger}$ \\
$\begin{array}{l}\text { Income } \\
\quad \text { Average or below }\end{array}$ & 1.00 & 1.00 & 1.00 \\
$\quad$ Above average & $1.88(0.93-3.77)^{\dagger}$ & $1.59(0.77-3.31)$ & $1.59(0.76-3.32)$ \\
Education & & & \\
$\quad$ High school or less & 1.00 & 1.00 & 1.00 \\
$\quad$ More than high school & $2.40(1.18-4.85)^{*}$ & $2.58(1.24-5.37)^{*}$ & $2.69(1.26-5.75)^{*}$ \\
Religiousness & 1.00 & 1.00 & 1.00 \\
$\quad$ Secular & $0.37(0.15-0.94)^{*}$ & $0.39(0.15-1.03)^{\dagger}$ & $0.41(0.15-1.09)^{\dagger}$ \\
$\quad$ Traditional & $0.69(0.22-2.18)$ & $0.74(0.23-2.35)$ & $0.77(0.24-2.52)$ \\
$\quad$ Religious & $1.02(0.18-5.84)$ & $1.20(0.20-7.27)$ & $1.09(0.19-6.47)$ \\
$\quad$ Very religious & & $0.88(0.81-0.96)^{* *}$ & $0.89(0.81-0.98)^{*}$ \\
T2 loss of resources & & & 1.00 \\
T2 social support-friends & & & $0.83(0.14-5.11)$ \\
$\quad$ Not at all & & & $1.49(0.26-8.42)$ \\
$\quad$ Some & & & $0.98(0.89-1.09)$ \\
$\quad$ To a very great degree & & & \\
T2 PTG & & &
\end{tabular}

Note. Significant odds ratios greater (less) than 1.00 are associated with a higher (lower) likelihood of resistance. $\mathrm{T} 1=$ baseline; $\mathrm{T} 2=12$-month follow-up; PTG $=$ posttraumatic growth

${ }^{\dagger} p<.10 . \quad{ }^{*} p<.05$. ${ }^{* * *} p<.01$. 
increases the reliability of the findings. It is also important to examine ethnic minority versus majority group comparisons, as minority group status is a clear risk factor.

Regarding intervention, the findings suggest that many individuals exposed to terrorism and war are symptomatic and might benefit from intervention and prevention efforts, whereas a substantive group remains resistant or recovers quickly. Importantly, our findings for economic and psychosocial resource loss provide avenues for intervention on these resource levels, as nothing or little can be done about income, gender, and religiousness. Finally, our findings suggest that posttraumatic growth may be counterproductive for people facing ongoing terrorism and war, which is quite different from findings for health-related threat (Helgeson et al., 2006).

Future studies might also identify those with a few symptoms but who are functioning well, as another sign of resilience, as our rather strict criteria are only one way to understand resilience. Those who experience some symptoms of depression or PTSD but who go to work, parent their children, and find pleasure in their lives are by some definition more resilient than are those who are symptom-free but not engaging in these kinds of activities. This suggests that there are several processes of resilience and resistance that are theoretically and practically interesting. These different trajectories also suggest the need for different kinds of intervention and prevention efforts.

\section{References}

Antonovsky, A. (1979). Health, stress, and coping. San Francisco: JosseyBass.

Bass, J. K., Bolton, P. A., \& Murray, L. K. (2007, September). Do not forget culture when studying mental health. Lancet, 370, 918-919.

Belle, D. (1990). Poverty and women's mental health. American Psychologist, 45, 385-389.

Bleich, A., Gelkopf, M., Melamed, Y., \& Solomon, Z. (2006). Mental health and resiliency following 44 months of terrorism: A survey of an Israeli national representative sample. BMC Medicine, 4, 21.

Bleich, A., Gelkopf, M., \& Solomon, Z. (2003). Exposure to terrorism, stress-related mental health symptoms, and coping behaviors among a nationally representative sample in Israel. Journal of the American Medical Association, 290, 612-620.

Bonanno, G. A. (2005). Clarifying and extending the construct of adult resilience. American Psychologist, 60, 265-267.

Bonanno, G. A., Galea, S., Bucciarelli, A., \& Vlahov, D. (2006). Psychological resilience after disaster: New York City in the aftermath of the September 11th terrorist attack. Psychological Science, 17, 181-186.

Bonanno, G. A., Galea, S., Bucciarelli, A., \& Vlahov, D. (2007). What predicts psychological resilience after disaster? The role of demographics, resources, and life stress. Journal of Consulting and Clinical Psychology, 75, 671-682.

Bonanno, G. A., Rennicke, C., \& Dekel, S. (2005). Self-enhancement among high-exposure survivors of the September 11th terrorist attack: Resilience or social maladjustment? Journal of Personality and Social Psychology, 88, 984-998.

Caplan, G. (1964). Principles of preventative psychiatry. New York: Basic Books.

Chen, Y. Y., \& Koenig, H. G. (2006). Traumatic stress and religion: Is there a relationship? A review of empirical findings. Journal of Religion and Health, 45, 371-381.

de Jong, J. T. V. M., Komproe, I. H., Van Ommeren, M., El Masri, M., Mesfin, A., Khaled, N., et al. (2001). Lifetime events and post-traumatic stress disorder in four post-conflict settings. Journal of the American Medical Association, 286, 555-562.

Ehring, T., Ehlers, A., \& Glucksman, E. (2008). Do cognitive models help in predicting the severity of posttraumatic stress disorder, phobia, and depression after motor vehicle accidents? Journal of Consulting and Clinical Psychology, 76, 219-230.

Foa, E. B., Riggs, D. S., Dancu, C. V., \& Rothbaum, B. O. (1993). Reliability and validity of a brief instrument for assessing posttraumatic stress disorder. Journal of Traumatic Stress, 6, 459-473.

Frankl, V. (1963). Man's search for meaning. Boston: Beacon Press.

Fredrickson, B., Tugade, M. M., Waugh, C. E., \& Larkin, G. R. (2003). What good are positive emotions in crises? A prospective study of resilience and emotions following the terrorist attacks on the United States on September 11th, 2001. Journal of Personality and Social Psychology, 84, 365-376.

Galea, S., Ahern, J., Resnick, H., Kilpatrick, D., Bucuvalas, M., Gold, J., et al. (2002). Psychological sequelae of the September 11 terrorist attacks in New York City. New England Journal of Medicine, 346, 982-987.

Galea, S., \& Resnick, H. (2005). Posttraumatic stress disorder in the general population after mass terrorist incidents: Considerations about the nature of exposure. CNS Spectrums, 10, 107-115.

Galea, S., \& Tracy, M. (2007). Participation rates in epidemiologic studies. Annals of Epidemiology, 17, 643-653.

Hatch, S. L., \& Dohrenwend, B. P. (2007). Distribution of traumatic and other stressful life events by race/ethnicity, gender, SES and age: A review of the research. American Journal of Psychiatry, 40, 313-332.

Helgeson, V. S., Reynolds, K. A., \& Tomich, P. L. (2006). A meta-analytic review of benefit finding and growth. Journal of Consulting and Clinical Psychology, 74, 797-816.

Hobfoll, S. E. (1989). Conservation of resources: A new attempt at conceptualizing stress. American Psychologist, 44, 513-524.

Hobfoll, S. E. (1998). Stress, culture, and community: The psychology and philosophy of stress. New York: Plenum Press.

Hobfoll, S. E. (2002). Social and psychological resources and adaptation. Review of General Psychology, 6, 307-324.

Hobfoll, S. E., Canetti-Nisim, D., \& Johnson, R. J. (2006). Exposure to terrorism, stress-related mental health symptoms, and defensive coping among Jews and Arabs in Israel. Journal of Consulting and Clinical Psychology, 74, 207-218.

Hobfoll, S. E., Canetti-Nisim, D., Johnson, R. J., Varley, J., Palmieri, P. A., \& Galea, S. (2008). The association of exposure, risk and resiliency factors with PTSD among Jews and Arabs exposed to repeated acts of terrorism in Israel. Journal of Traumatic Stress, 21, 9-21.

Hobfoll, S. E., Hall, B. J., Canetti-Nisim, D., Galea, S., Johnson, R. J., \& Palmieri, P. (2007). Refining our understanding of traumatic growth in the face of terrorism: Moving from meaning cognitions to doing what is meaningful. Applied Psychology: An International Journal, 56, 345366.

Hobfoll, S. E., Tracy, M., \& Galea, S. (2006). The impact of resource loss and "traumatic growth" on probable PTSD and depression following terrorist attacks. Journal of Traumatic Stress, 19, 867-878.

Layne, C. M., Warren, J., Shalev, A., \& Watson, P. (2007). Risk, vulnerability, resistance, and resilience: Towards an integrative conceptualization of posttraumatic adaptation. In M. J. Friedman, T. M. Kean, \& P. A. Resick (Eds.), PTSD: Science and practice: A comprehensive handbook (pp. 497-520). New York: Guilford Press.

Norris, F. H. (2001). Measuring exposure to the events of September 11, 2001. Retrieved from National Institutes of Health, Office of Behavioral and Social Sciences Research: http://obssr.od.nih.gov/activities/911/ attack.htm

Norris, F. H., Friedman, M. J., Watson, P. J., Byrne, C. M., Diaz, E., \& Kaniasty, K. (2002). 60,000 disaster victims speak: Part I. An empirical 
review of the empirical literature, 1981-2001. Psychiatry: Interpersonal and Biological Processes, 65(3), 207-239.

Norris, F. H., \& Kaniasty, K. (1996). Received and perceived social support in times of stress: A test of the social support deterioration deterrence model. Journal of Personality and Social Psychology, 71, 498-511.

Norris, F. H., Stevens, S. P., Pfefferbaum, B., Wyche, K. F., \& Pfefferbaum, R. L. (2007). Community resilience as a metaphor, theory, set of capacities, and strategy for intervention. American Journal of Cоттиnity Psychology, 41, 127-150.

Punamäki, R.-L., Komproe, I. H., Qouta, S., Elmasri, M., \& de Jong, J. T. V. M. (2005). The role of peritraumatic dissociation and gender in the association between trauma and mental health in a Palestinian community sample. American Journal of Psychiatry, 162, 545-551.

Sarason, I. G., Sarason, B. R., Shearin, E. N., \& Pierce, G. R. (1987). A brief measure of social support: Practical and theoretical implications. Journal of Social and Personal Relationships, 4, 497-510.

Scholte, W. F., Olff, M., Ventevogel, P., de Vries, G. J., Jansveld, E., Cardozo, B. L., et al. (2004). Mental health symptoms following war and repression in eastern Afghanistan. Journal of the American Medical Association, 292, 585-593.

Shalev, A. Y., Tuval, R., Frenkiel-Fishman, S., Hadar, H., \& Eth, S. (2006). Psychological responses to continuous terror: A study of two communities in Israel. American Journal of Psychiatry, 163, 667-673.

Silove, D. (1999). The psychosocial effects of torture, mass human rights violations, and refugee trauma: Toward an integrated conceptual framework. Journal of Nervous and Mental Disease, 187, 200-2007.
Smooha, S. (2004). Index of Jewish-Arab relations in Israel. Haifa, Israel: University of Haifa.

Somer, E., Ruvio, A., Soref, E., \& Sever, I. (2005). Terrorism, distress and coping: High versus low impact regions and direct versus indirect civilian exposure. Anxiety, Stress, and Coping, 18, 165-182.

Spitzer, R. L., Kroenke, K., \& Williams, J. B. W. (1999). Validation and utility of a self-report version of Prime-MD. Journal of the American Medical Association, 282, 1737-1744.

Stasko, E. C., \& Ickovics, J. R. (2007). Traumatic growth in the face of terrorism: Threshold effects and action-based growth. Applied Psychology: An International Review, 56, 386-395.

Tedeschi, R. G., \& Calhoun, L. G. (2004). Posttraumatic growth: Conceptual foundations and empirical evidence. Psychological Inquiry, 15, $1-18$.

Tracy, M., Hobfoll, S. E., Canetti-Nisim, D., \& Galea, S. (2008). Predictors of depressive symptoms among Israeli Jews and Arabs during the $\mathrm{Al}$ Aqsa Intifada: A population-based cohort study. Annals of Epidemiology, 18, 447-457.

Zoellner, T., \& Maercker, A. (2006). Posttraumatic growth in clinical psychology: A critical review and introduction of a two component model. Clinical Psychology Review, 26(5), 626-653.

Received December 14, 2007 Revision received October 9, 2008 Accepted October 10, 2008 